\title{
The Reaction between Diphenylmethane and Butadiene with Organolithium Compounds
}

\author{
Teruo Yamaguchi, Tadashi Narita, and Teiji Tsuruta \\ Department of Synthetic Chemistry, Faculty of Engineering, \\ University of Tokyo, Japan.
}

(Received December 20, 1971)

\begin{abstract}
The reaction between diphenylmethane and butadiene with organolithium compounds was investigated in order to obtain telomers containing one butadiene unit in high selectivity. The lithium salt of methoxyethanol $\left(\mathrm{CH}_{3} \mathrm{OCH}_{2} \mathrm{CH}_{2} \mathrm{OLi}\right)$, $N, N, N^{\prime}, N^{\prime}$-tetramethylethylenediamine(TMEDA), hexamethylphosphoric triamide(HMPT) and their related compounds were used as complexing agents for lithium alkyl. 5,5Diphenyl-2-pentene and 5,5-diphenyl-1-pentene (DPPE) were obtained in high yields using these catalyst systems. The influence of molar ratio, [complexing agent]/[lithium alkyl], on the yield of DPPE was studied and the reaction was found to depend strongly on the nature of complexing agent. In order to discuss the specificity of the various catalyst systems, the metalation reaction of diphenylmethane was investigated.
\end{abstract}

KEY WORDS Anionic telomerization / Butadiene / Diphenylmethane / $n$-Butyllithium / Methoxyethanol / $N, N, N^{\prime}, N^{\prime}$-Tetramethylethylenediamine / Hexamethylphosphoric triamide / 5,5phenylDi2-pentene /

It was reported in previous papers ${ }^{1,2}$ that the reactivity of styrene at an early stage of the styrene-butadiene copolymerization was increased by $n$-butyllithium( $n$ - BuLi) $-\mathrm{CH}_{3} \mathrm{OCH}_{2}$. $\mathrm{CH}_{2} \mathrm{OLi}$ catalyst system in toluene and that copolymers containing more styrene units than the feed monomer ratio were formed. The metalation reaction of toluene to produce benzyllithium was observed to take place with this catalyst system. ${ }^{2}$ This paper presents the results of a study on a new route to the synthesis of olefinic hydrocarbons by applying the metalation reaction of diphenylmethane in combination with the addition reaction of butadiene with the metalated diphenylmethane.

Narita and Tsuruta proposed ${ }^{3}$ a term "coordination-agent-separated ion pair" as shown in [I], which was considered to be active species of $n$ - BuLi- $\mathrm{CH}_{3} \mathrm{OCH}_{2} \mathrm{CH}_{2} \mathrm{OLi}$ system, by means of measurements of electronic spectra of 1,1-diphenyl-n-hexyllithium- $\mathrm{CH}_{3} \mathrm{OCH}_{2} \mathrm{CH}_{2} \mathrm{OLi}$ system and of 9-fluorenyllithium- $-\mathrm{CH}_{3} \mathrm{OCH}_{2} \mathrm{CH}_{2} \mathrm{OLi}$ system.

An $n$-BuLi-amine catalyst system was investigated by Eberhardt, et al., ${ }^{4}$ for the telomerization reaction of aromatic hydrocarbon and

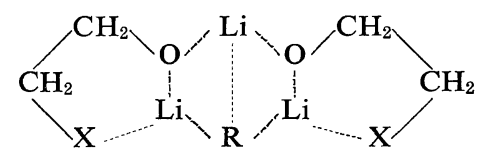

[I]

R, alkyl- or aryl-;

$\mathrm{X},-\mathrm{OCH}_{3}$ or $-\mathrm{N}\left(\mathrm{CH}_{3}\right)_{2}$.

ethylene in which straight-chain alkyl benzenes having various chain lengths were formed. Asahara and his coworkers ${ }^{5}$ carried out the telomerization reaction by using lithium alkyl$N, N, N^{\prime}, N^{\prime}$-tetramethylethylenediamine(TMEDA) and its derivatives. Kambara and his coworkers $^{6}$ reported that in an anionic polymerization of butadiene initiated by metallic sodium in toluene-tetrahydrofuran(THF) mixture, a transfer reaction was caused by toluene, which resulted in the formation of the telomer $\mathrm{C}_{6} \mathrm{H}_{5} \mathrm{CH}_{2}\left(\mathrm{C}_{4} \mathrm{H}_{6}\right)_{n} \mathrm{H}$. The ratio of telomer containing one butadiene unit $(n=1)$, mostly 5-phenyl-trans-2-pentene, to all telomers was found to be less than $60 \%$.

In this paper the reaction of butadiene with diphenylmethane was studied to obtain telomers containing one butadiene unit. Diphenylmethane (pKa 35) is a stronger acid than toluene 
(pKa 37) and it is expected to obtain one to one telomer in high yield. The reaction scheme is considered to be described as follows

$$
\begin{aligned}
& \text { (i) Metalation } \mathrm{Ph}_{2} \mathrm{CH}_{2}+n-\mathrm{BuLi} \cdot \mathrm{D} \longrightarrow \mathrm{Ph}_{2} \mathrm{CHLi} \cdot \mathrm{D}+n-\mathrm{BuH} \\
& \text { (ii) Butenylation } \mathrm{Ph}_{2} \mathrm{CHLi} \cdot \mathrm{D}+\mathrm{C}_{4} \mathrm{H}_{6} \longrightarrow \mathrm{Ph}_{2} \mathrm{CH}\left(\mathrm{C}_{4} \mathrm{H}_{6}\right) \mathrm{Li} \cdot \mathrm{D} \\
& \text { (iii) Transmetalation } \uparrow \\
& \\
& \mathrm{Ph}_{2} \mathrm{CH}\left(\mathrm{C}_{4} \mathrm{H}_{6}\right) \mathrm{Li} \cdot \mathrm{D}+\mathrm{Ph}_{2} \mathrm{CH}_{2} \longrightarrow \mathrm{Ph}_{2} \mathrm{CH}\left(\mathrm{C}_{4} \mathrm{H}_{6}\right) \mathrm{H}+\mathrm{Ph}_{2} \mathrm{CHLi} \cdot \mathrm{D}
\end{aligned}
$$

in which $\mathrm{D}$ is a complexing agent which forms complexes with lithium alkyl; for examples, lithium salt of methoxyethanol $\left(\mathrm{CH}_{3} \mathrm{OCH}_{2} \mathrm{CH}_{2}\right.$. $\mathrm{OLi})$ and its analogues such as $\left(\mathrm{CH}_{3}\right)_{2} \mathrm{NCH}_{2}$. $\mathrm{CH}_{2} \mathrm{OLi}$, or lithium salt of tetrahydrofurfuryl alcohol, and TMEDA, hexamethylphosphoric triamide (HMPT) and dimethoxyethane (DME).

\section{EXPERIMENTAL}

\section{Reagents}

Diphenylmethane was synthesized by the Friedel-Crafts reaction ${ }^{7}$ from benzene and benzyl chloride in the presence of anhydrous aluminum chloride and was purified by distillation under reduced pressure, bp $80-81^{\circ} \mathrm{C}(1.0$ $\mathrm{mm}$ ). Butadiene (Japan Synthetic Rubber Co., purity $99.6 \%$ ) was purified by the usual method in the vapor phase and was trapped at, $-78^{\circ} \mathrm{C}$. $n$-BuLi was prepared from $n$-BuCl and $\mathrm{Li}$ metal in purified petroleum ether under nitrogen ${ }^{8}$ and a solution in cyclohexane was used after the determination of its concentration by Gilman's double titration method. ${ }^{9} \quad \mathrm{CH}_{3} \mathrm{OCH}_{2} \mathrm{CH}_{2} \mathrm{OH}$ $\left[125^{\circ} \mathrm{C}(760 \mathrm{~mm})\right]$, TMEDA $\left[120-121^{\circ} \mathrm{C}(760\right.$ $\mathrm{mm})]$, and $\mathrm{HMPT}\left[55^{\circ} \mathrm{C}(1.0 \mathrm{~mm})\right]$ were refluxed over $\mathrm{CaH}_{2}$ and distilled under nitrogen. Other reagents and solvents were purified by the usual methods under nitrogen.

The Reaction between Butadiene and Diphenylmethane

A $200 \mathrm{~m} l$-four-necked round-bottom flask equipped with a reflux condenser with Dry Icemethanol refrigerant and an inlet for butadiene was used. Diphenylmethane $(50 \mathrm{ml}=0.30 \mathrm{~mol})$ and a complexing agent were added to the magnetically stirred solution of $n$-BuLi (3.0 $\mathrm{mmol}$ ) by a syringe under nitrogen atmosphere. The reactor was heated at a definite temperature $\left(50^{\circ} \mathrm{C}\right)$ and butadiene $(8.0 \mathrm{ml}=0.107 \mathrm{~mol})$ vapor was absorbed slowly in the reaction system for $2.5 \mathrm{hr}$. After the reaction was completed, the reactor was cooled and the catalyst deactivated by adding methanol $(2 \mathrm{ml})$. The reaction product was washed with acidic water and then dried with anhydrous sodium sulfate. The products were analysed by vapor-phase chromatography (VPC) under the condition: a $5 \mathrm{~mm} \times 6 \mathrm{~m}$ column of poly(ethylene glycol) on Diasolid L $15 \%$ at $230^{\circ} \mathrm{C}$ for the column temperature with a hydrogen flow rate of $c a .30$ $\mathrm{ml} / \mathrm{min}$. The yield of telomer was calculated on the basis of feed moles of butadiene.

\section{Isolation of Reaction Products}

Telomer containing one butadiene unit was a mixture of three isomers, 5,5-diphenyl-cis-2pentene, 5,5-diphenyl-trans-2-pentene and 5,5diphenyl-1-pentene. 5,5-Diphenyl-cis-2-pentene was isolated by preparative VPC. An authentic sample of 5,5-diphenyl-trans-2-pentene was synthesized from $\mathrm{Ph}_{2} \mathrm{CHLi}$ and trans-crotyl chloride. 5,5-Diphenyl-1-pentene was also synthesized from $\mathrm{Ph}_{2} \mathrm{CHLi}$ and 4-chloro-1-butene which was prepared from 3-buten-1-ol and thionyl chloride.

The hydrogenation of DPPE to 1,1-diphenylpentane was carried out in an autoclave catalyzed by Raney nickel activated by alkali at $\mathrm{H}_{2} \quad 40-50 \mathrm{~kg} / \mathrm{cm}^{2}$.

\section{Metalation of Diphenylmethane}

The metalation yield of diphenylmethane by $n$-BuLi was measured by VPC to determine pentane and diphenylethane using dimethyl sulfate [bp $\left.75^{\circ} \mathrm{C}(15 \mathrm{~mm})\right]$ as methylating agent.

\section{RESULTS}

\section{Identification of Reaction Products}

The diphenylpentene (DPPE) formed by the reaction between diphenylmethane and butadiene was a mixture of three isomers, which were identified with 5,5-diphenyl-cis-2-pentene, 5,5-diphenyl-trans-2-pentene and 5,5-diphenyl-1pentene from IR and NMR spectra. 
The Reaction between Diphenylmethane and Butadiene<smiles>CC=CCCC=O</smiles>

cis-DPPE<smiles>CC=CCC=O</smiles>

trans-DPPE<smiles>C=CCCC(C)C</smiles>

vinyl-DPPE

Table I. Analysis of products

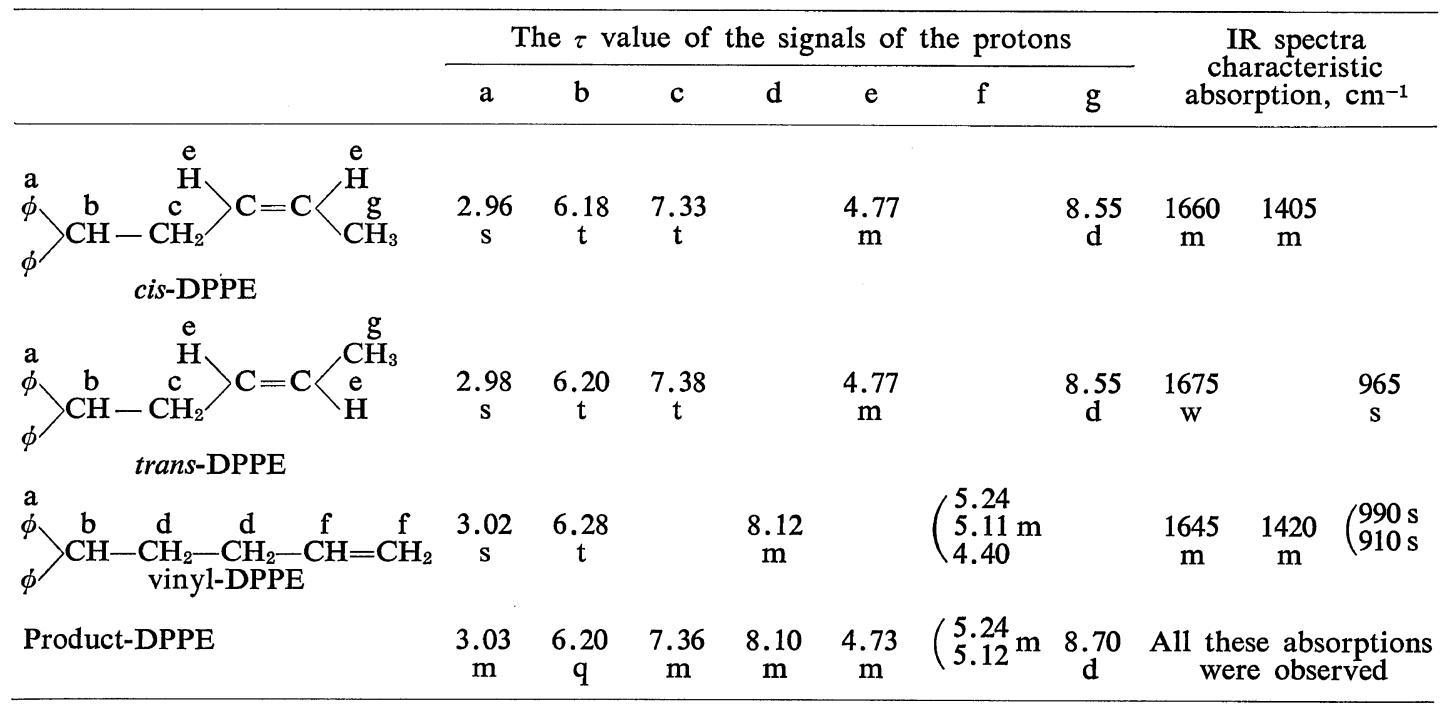

Spectral data of the products are shown in Table I.

Mass spectrum of DPPE showed that parent peak $\left(\mathrm{M}^{+}\right)$was $\mathrm{m} / \mathrm{e} 222$ and base peak m/e 167.<smiles>CCCCCCC(CC)C(CCCC)c1ccccc1</smiles>

Elemental Analysis of DPPE. Calcd for reaction products $\mathrm{C}_{17} \mathrm{H}_{18}$ : C, 91.84; H, 8.16. Found: C, 92.02; $\mathrm{H}, 8.23$.

Influence of Molar Ratio between $n-B u L i$ and Complexing Agents Upon the Yield of DPPE

(i) $n-\mathrm{BuLi}-\mathrm{CH}_{3} \mathrm{OCH}_{2} \mathrm{CH}_{2} \mathrm{OLi}$ System. The results with $n$ - BuLi- $\mathrm{CH}_{3} \mathrm{OCH}_{2} \mathrm{CH}_{2} \mathrm{OLi}$ system are shown in Figure 1. The yield of DPPE was very low when $[\mathrm{OLi}] /[\mathrm{CLi}]$ (molar ratio of $\mathrm{CH}_{3} \mathrm{OCH}_{2} \mathrm{CH}_{2} \mathrm{OLi}$ to $n$ - $\mathrm{BuLi}$ ) was $0-1.0$, but at $[\mathrm{OLi}] /[\mathrm{CLi}]=2.0$ the yield of DPPE was increased remarkably and was almost constant when $[\mathrm{OLi}] /[\mathrm{CLi}]=4.0-6.0$. This catalyst system was heterogenous. Temperature dependence of the yield of DPPE at $[\mathrm{OLi}] /[\mathrm{CLi}]=2.0$ is shown in Figure 2. The yield of DPPE increased with an increase in temperature and showed a maximum at $50-70^{\circ} \mathrm{C}$ and decreased at $90^{\circ} \mathrm{C}$. The ratio of cis structure decreased slightly with an increase in temperature as expected.

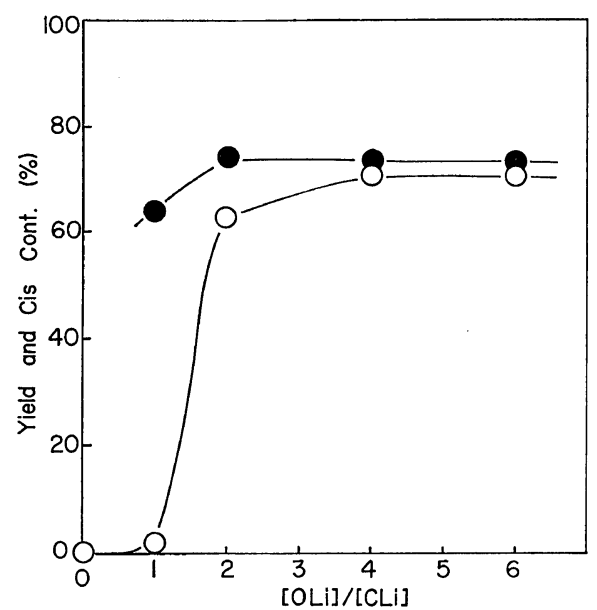

Figure 1. Reaction of diphenylmethane and butadiene by $n-\mathrm{BuLi}-\mathrm{CH}_{3} \mathrm{OCH}_{2} \mathrm{CH}_{2} \mathrm{OLi}$ system: $\bigcirc$, yield of DPPE (\% on $\left.[\mathrm{Bd}]_{0}\right) ; \bullet$, cis content $(\%$ in DPPE).

Reaction conditions: $n$-BuLi, $3 \mathrm{mmol} ; \mathrm{Ph}_{2} \mathrm{CH}_{2}, 50$ $\mathrm{ml} ;[\mathrm{Bd}]_{0}, 8.0 \mathrm{ml}$ at $-78^{\circ} \mathrm{C}$; temperature, $50^{\circ} \mathrm{C}$; $2.5 \mathrm{hr}$. 
Lithium alcoholates of dimethylaminoethanol and tetrahydrofurfuryl alcohol were used because these compounds were expected to show a

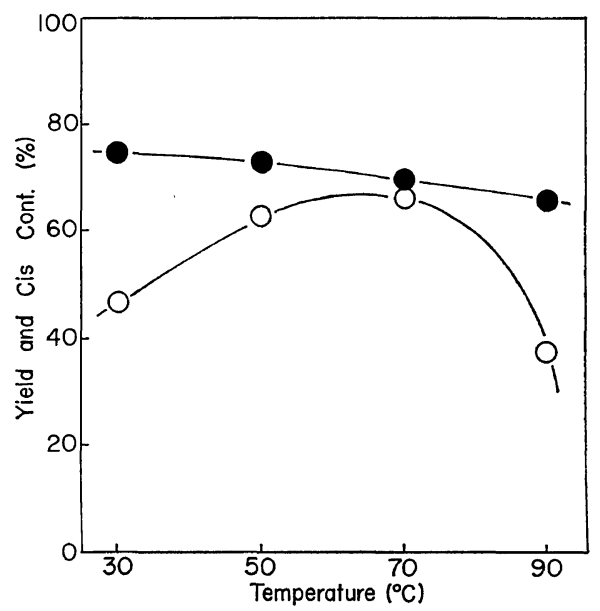

Figure 2. Reaction of diphenylmethane and butadiene by $n$ - $\mathrm{BuLi}-\mathrm{CH}_{3} \mathrm{OCH}_{2} \mathrm{CH}_{2} \mathrm{OLi}$ system (temperature dependence): $\bigcirc$, yield of DPPE ( $\%$ on $\left.[\mathrm{Bd}]_{0}\right) ; 0$, cis content (\% in DPPE).

Reaction conditions: $n$-BuLi, $3 \mathrm{mmol} ; \mathrm{Ph}_{2} \mathrm{CH}_{2}, 50$ $\mathrm{m} l ;[\mathrm{Bd}]_{0}, 8.0 \mathrm{~m} l$ at $-78^{\circ} \mathrm{C} ;[\mathrm{OLi}] /[\mathrm{CLi}]=2 ; 2.5 \mathrm{hr}$.

Table II. Reaction of diphenylmethane and butadiene by various catalyst systems ${ }^{a}$

\begin{tabular}{lccc}
\hline D, donor & $\frac{[\mathrm{D}]}{[\mathrm{CLi}]}$ & $\frac{[\mathrm{DPPE}]}{[\mathrm{Bd}]_{0}} \times 100$ & $\begin{array}{c}\text { cis } \\
\text { Content }\end{array}$ \\
\hline $\mathrm{CH}_{3} \mathrm{OCH}_{2} \mathrm{CH}_{2} \mathrm{OCH}_{3}$ & $\left\{\begin{array}{r}2 \\
4\end{array}\right.$ & 6 & 62 \\
$\left(\mathrm{CH}_{3}\right)_{2} \mathrm{NCH}_{2} \mathrm{CH}_{2} \mathrm{OLi}$ & 4 & 68 & - \\
$\mathrm{CH}_{2} \mathrm{OLi}$ & 4 & 18 & 72 \\
\hline
\end{tabular}

a $n$-BuLi, $3 \mathrm{mmol} ; \mathrm{Ph}_{2} \mathrm{CH}_{2}, 50 \mathrm{ml} ;[\mathrm{Bd}]_{0}, 8.0 \mathrm{~m} l$ at $-78^{\circ} \mathrm{C}$; temp, $50^{\circ} \mathrm{C}$; time, $2.5 \mathrm{hr}$. similar effect to that $\mathrm{CH}_{3} \mathrm{OCH}_{2} \mathrm{CH}_{2} \mathrm{OLi}$. Dimethoxyethane did not form a stable complex with $n$-BuLi under these conditions and anionic species seemed to be decomposed. These results are summarized in Table II. $n-\mathrm{BuLi}-\left(\mathrm{CH}_{3}\right)_{2}$. $\mathrm{NCH}_{2} \mathrm{CH}_{2} \mathrm{OLi}$ catalyst system showed almost similar activity to that of the $n-\mathrm{BuLi}-\mathrm{CH}_{3}$. $\mathrm{OCH}_{2} \mathrm{CH}_{2} \mathrm{OLi}$ system. The $n$ - $\mathrm{BuLi}-\left(\mathrm{C}_{4} \mathrm{H}_{7} \mathrm{O}\right)$. $\mathrm{CH}_{2} \mathrm{OLi}$ catalyst system showed the same value for the ratio of cis structure of DPPE formed, but the yield of the addition product was very low in comparison with that of the $n$-BuLi$\mathrm{CH}_{3} \mathrm{OCH}_{2} \mathrm{CH}_{2} \mathrm{OLi}$ system.

Table III shows the results of equimolar reaction of diphenylmethane and butadiene with $n$ - $\mathrm{BuLi}-\mathrm{CH}_{3} \mathrm{OCH}_{2} \mathrm{CH}_{2} \mathrm{OLi}$ catalyst system. In the lower concentration of diphenylmethane, the yield of DPPE was decreased markedly due to the formation of oligomers of butadiene. When THF was added to $n$-BuLi-alcoholate system, the yield in the equimolar reaction was increased. When dioxane was added as solvent under these reaction conditions, the decomposition of dioxane took place.

(ii) $n$-BuLi-TMEDA System. The results obtained by changing the molar ratio of [TMEDA] $] /[n-\mathrm{BuLi}]$ are summarized in Figure 3. The yield of DPPE increased gradually to over $70 \%$ with an increase in [TMEDA] $/[n-\mathrm{BuLi}]$ ratio till the ratio reached four. This system was homogeneous contrarily to $n-\mathrm{BuLi}-\mathrm{CH}_{3}$. $\mathrm{OCH}_{2} \mathrm{CH}_{2} \mathrm{OLi}$ system. The addition of THF to this system increased the yield of DPPE but decreased the cis contents in the reaction products.

(iii) $n$-BuLi-HMPT System. The results in this catalyst system are shown in Figure 4. It was characteristic for this system that the yield

Table III. Equimolar reaction of diphenylmethane and butadiene

\begin{tabular}{|c|c|c|c|c|c|}
\hline $\mathrm{D}$, donor & $\frac{[\mathrm{D}]}{[\mathrm{CLi}]}$ & Solvent & $\mathrm{m} l$ & $\frac{\mathrm{DPPE}}{[\mathrm{Bd}]_{0}} \times 100$ & cis Content \\
\hline $\mathrm{CH}_{3} \mathrm{OCH}_{2} \mathrm{CH}_{2} \mathrm{OLi}$ & 2 & & & 12 & 69 \\
\hline None & 0 & THF & 32 & 19 & 72 \\
\hline $\mathrm{CH}_{3} \mathrm{OCH}_{2} \mathrm{CH}_{2} \mathrm{OLi}$ & 2 & THF & 32 & 49 & 74 \\
\hline $\mathrm{CH}_{3} \mathrm{OCH}_{2} \mathrm{CH}_{2} \mathrm{OLi}$ & 2 & $\mathbf{H}$ & 32 & 19 & 71 \\
\hline
\end{tabular}

a $n$-BuLi, $3 \mathrm{mmol} ; \mathrm{Ph}_{2} \mathrm{CH}_{2}=[\mathrm{Bd}]_{0}, 107 \mathrm{mmol}$; temp, $50^{\circ} \mathrm{C}$; time, $2.2-3.3 \mathrm{hr}$. 
The Reaction between Diphenylmethane and Butadiene

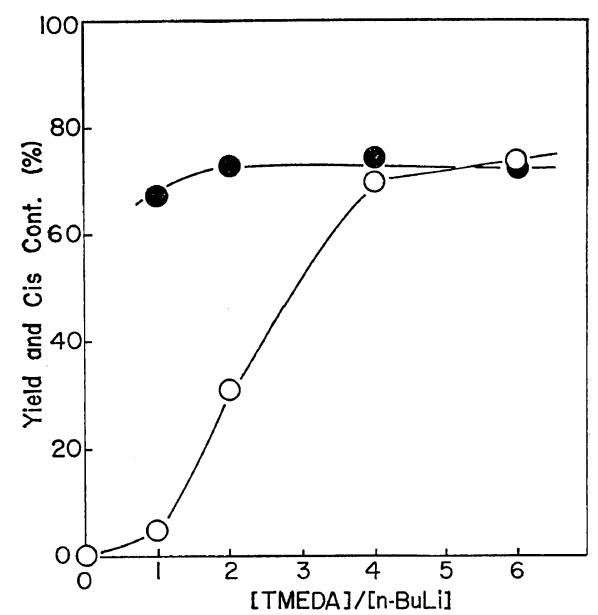

Figure 3. Reaction of diphenylmethane and butadiene by $n$-BuLi-TMEDA system: $\bigcirc$, yield of DPPE ( $\%$ on $\left.[\mathrm{Bd}]_{0}\right) ; 0$, cis content (\% in DPPE). Reaction conditions: $n$-BuLi, 3 mmol; $\mathrm{Ph}_{2} \mathrm{CH}_{2}, 50$ $\mathrm{ml} ;[\mathrm{Bd}]_{0}, 8.0 \mathrm{ml}$ at $-78^{\circ} \mathrm{C}$; temp, $50^{\circ} \mathrm{C} ; 2.5 \mathrm{hr}$.

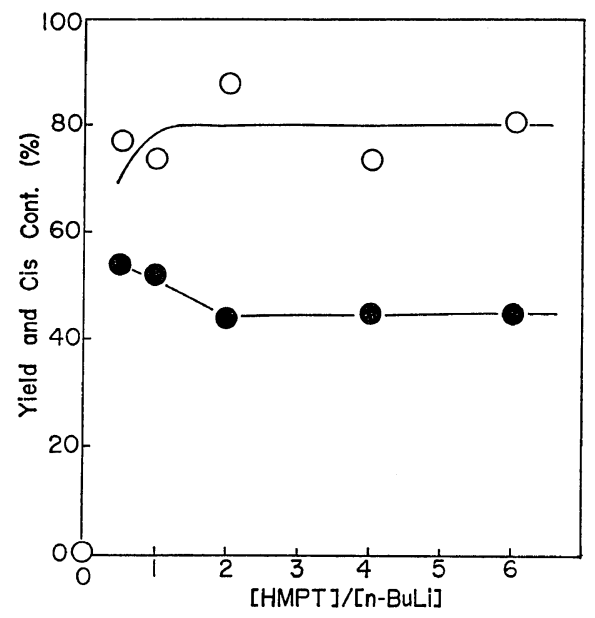

Figure 4. Reaction of diphenylmethane and butadiene by $n$-BuLi-HMPT system: $\bigcirc$, yield of DPPE ( $\%$ on $\left.[\mathrm{Bd}]_{0}\right) ; 0$, cis content ( $\%$ in DPPE). Reaction conditions: $n$-BuLi, $3 \mathrm{mmol} ; \mathrm{Ph}_{2} \mathrm{CH}_{2}, 50$ $\mathrm{ml} ;[\mathrm{Bd}]_{0}, 8.0 \mathrm{ml}$ at $-78^{\circ} \mathrm{C}$; temp, $50^{\circ} \mathrm{C} ; 2.5 \mathrm{hr}$.

of DPPE was high enough (about 80\%) even if $[\mathrm{HMPT}] /[n-\mathrm{BuLi}]$ ratio was less than 1.0 . The isomer distribution in DPPE, however, was remarkably different from the other systems, 5,5diphenyl-trans-2-pentene being the main product. This catalyst system was also homogeneous.

The reaction between diphenylmethane and
Table IV. Reaction of diphenylmethane and butadiene by alkali metal-HMPT system ${ }^{\mathrm{a}}$

\begin{tabular}{|c|c|c|}
\hline M & $\frac{\mathrm{DPPE}}{[\mathrm{Bd}]_{0}} \times 100$ & cis Content \\
\hline $\mathrm{Li}$ & 86 & 45 \\
\hline $\mathrm{Na}$ & 88 & 51 \\
\hline $\mathbf{K}$ & 93 & 42 \\
\hline
\end{tabular}

a Catalyst: blue solution, $3.0 \mathrm{ml}$ (HMPT $10 \mathrm{~m} l$, alkali metal); $\mathrm{Ph}_{2} \mathrm{CH}_{2}, 50 \mathrm{ml} ;[\mathrm{Bd}]_{0}, 8.0 \mathrm{ml}$ at $-78^{\circ} \mathrm{C}$; temp, $50^{\circ} \mathrm{C}$, time, $2.5 \mathrm{hr}$.

butadiene was carried out also by alkali metalHMPT system and these results are shown in Table IV. HMPT dissolved alkali metals to form blue solution which contained radicalanions of HMPT. ${ }^{10}$ This radical-anion and the decomposition product of HMPT, lithium dimethylamide, were both good metalating agents. The yield of DPPE obtained from this system was about $90 \%$.

\section{DISCUSSION}

In order to make clear the peculiarity of each catalyst system described above, the metalation reaction of diphenylmethane with each of them was measured. Since diphenylmethane was metalated by $n$-BuLi-complexing agent system to form the red diphenylmethyl anion (eq 4), dimethyl sulfate was used as alkylating agent of the organolithium compounds according to eq 5 and 6:

$$
\begin{aligned}
& \mathrm{Ph}_{2} \mathrm{CH}_{2}+n-\mathrm{BuLi} \cdot \mathrm{D} \\
& \mathrm{Ph}_{2} \mathrm{CHLi} \cdot \mathrm{D}+n-\mathrm{BuH} \\
& \text { red } \\
& \mathrm{Ph}_{2} \mathrm{CHLi} \cdot \mathrm{D}+\left(\mathrm{CH}_{3}\right)_{2} \mathrm{SO}_{4} \\
& \quad \mathrm{Ph}_{2} \mathrm{CH}-\mathrm{CH}_{3}+\mathrm{CH}_{3} \mathrm{OSO}_{3} \mathrm{Li} \\
& n-\mathrm{BuLi} \cdot \mathrm{D}+\left(\mathrm{CH}_{3}\right)_{2} \mathrm{SO}_{4} \\
& \longrightarrow n-\text { Pentane }+\mathrm{CH}_{3} \mathrm{OSO}_{3} \mathrm{Li}
\end{aligned}
$$

$n$-Pentane and 1,1-diphenylethane were analyzed by VPC.

(i) $\mathrm{n}$ - $\mathrm{BuLi}-\mathrm{CH}_{3} \mathrm{OCH}_{2} \mathrm{CH}_{2} \mathrm{OLi}$ System. The results are shown in Table $\mathrm{V}$. The recovery of pentane and diphenylethane tended to decrease as the value of $[\mathrm{OLi}] /[\mathrm{CLi}]$ increased, and this seemed to indicate possibilities of the reactions between organolithium compounds and $\mathrm{CH}_{3} \mathrm{OCH}_{2} \mathrm{CH}_{2} \mathrm{OLi}$. The metalation yield of 
Table V. Metalation of diphenylmethane by $n-\mathrm{BuLi}-\mathrm{CH}_{3} \mathrm{OCH}_{2} \mathrm{CH}_{2} \mathrm{OLi}$ system ${ }^{\text {a }}$

\begin{tabular}{ccccc}
\hline [OLi] & (i) $\begin{array}{c}n-\mathrm{BuLi}-\mathrm{CH}_{3} \mathrm{OCH}_{2} \mathrm{CH}_{2} \mathrm{OLi} \\
\text { [CLi] }\end{array}$ & \multicolumn{2}{c}{ (ii) $n$ - $\mathrm{nuLi}-\mathrm{CH}_{3} \mathrm{OCH}_{2} \mathrm{CH}_{2} \mathrm{OLi}-\mathrm{Ph}_{2} \mathrm{CH}_{2}$} & Extent of metalation, \\
\cline { 3 - 5 } & & $n$-Pentane, mmol & Diphenylethane, mmol & \\
\hline 0 & 0.97 & 0.97 & 0 & 0 \\
1 & 0.97 & 0.90 & 0.05 & 5 \\
2 & 1.01 & 0.80 & 0.16 & 16 \\
4 & 0.70 & 0.57 & 0.10 & 14 \\
\hline
\end{tabular}

a Reaction conditions: $n-\mathrm{C}_{4} \mathrm{H}_{9} \mathrm{Li}, 1.0 \mathrm{mmol}$; cyclohexane, $10 \mathrm{ml} ; \mathrm{Ph}_{2} \mathrm{CH}_{2}, 1.0 \mathrm{ml}$; room temp, $30 \mathrm{~min}$; dimethyl sulfate (methylating agent) $1.0 \mathrm{~m} l$.

diphenylmethane was measured at room temperature after $30 \mathrm{~min}$ reaction time. Under these reaction conditions, the extent of metalation was below $20 \%$.

(ii) n-BuLi-TMEDA System. Some ditertiary amines such as TMEDA were reported to form organolithium complexes such as [II]. This was found to be a relatively stable, pale yellow oil and possessed remarkable carbanion reactivity. ${ }^{11}$<smiles>CCC[Al]1[Al](C)N(C)CC[N+]1(C)C</smiles>

[II]

It is well known that this complex metalated aromatic hydrocarbons. The results of the metalation of diphenylmethane are shown in Figure 5. As shown in Figure 5 (i), this complex itself generated $n$-butane at $20-30 \%$ to $n$-BuLi owing to the metalation of TMEDA. ${ }^{11}$
Diphenylmethane was quantitatively metalated when [TMEDA] $/[n-\mathrm{BuLi}]$ ratio was 1.0 or more. Since the metalation curve of diphenylmethane almost overlapped with the curve for butane formation as shown in Figure 5 (ii), a complex [III] formed by metalation of TMEDA is also good metalating agent of diphenylmethane.

(iii) $n$-BuLi-HMPT System. $n$-BuLi reacted with HMPT exothermically with the evolution of gaseous products. The results of the reaction between $n$-BuLi and HMPT and the metalation reaction of diphenylmethane are shown in Figure 6. Half of the total amount of $n-\mathrm{BuLi}$ was changed to $n$-butane, and no $n$-BuLi species remained in this system.

Dimethylamine was obtained by the hydrolysis after the reaction between $n$-BuLi and HMPT. Alkali metal is known to decompose HMPT to produce dimethylamide ion and diamide phosphite ion (eq 7):

$$
\begin{array}{cl}
\mathrm{O}=\begin{array}{c}
\mathrm{P}\left(\mathrm{NMe}_{2}\right)_{3} \\
+ \\
\mathrm{M}
\end{array} & \longrightarrow\left[\mathrm{O}=\mathrm{P}\left(\mathrm{NMe}_{2}\right)_{3}\right]^{(-)} \mathrm{M}^{(+)} \\
& \stackrel{\mathrm{M}}{\longrightarrow} \underset{\left(\mathrm{Me}_{2} \mathrm{~N}\right)_{2} \mathrm{P}^{(-)}=\mathrm{OM}^{(+)}}{\mathrm{Me}_{2} \mathrm{~N}^{(-)} \mathrm{M}^{(+)}}
\end{array}
$$

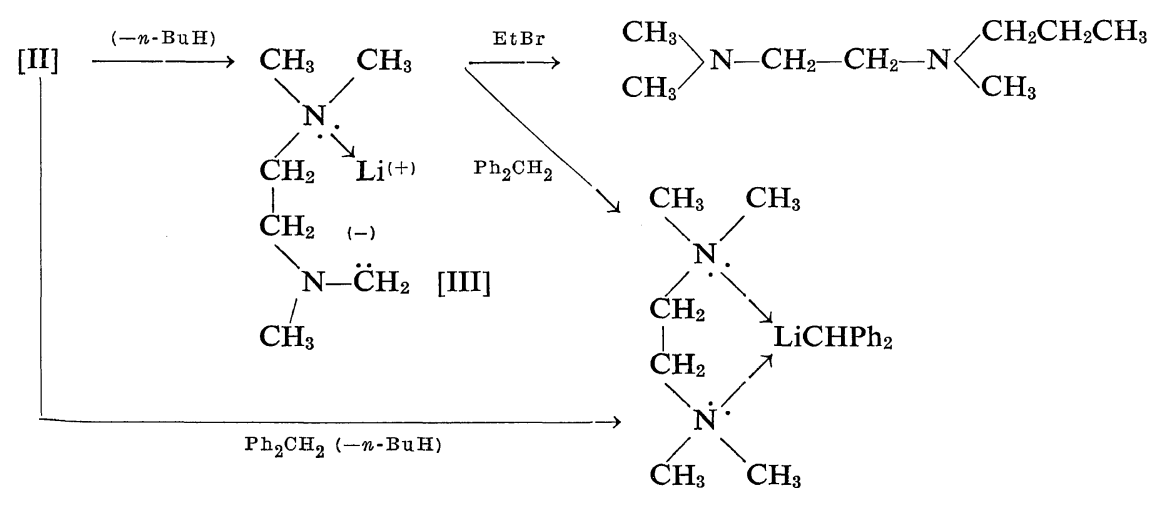


The Reaction between Diphenylmethane and Butadiene
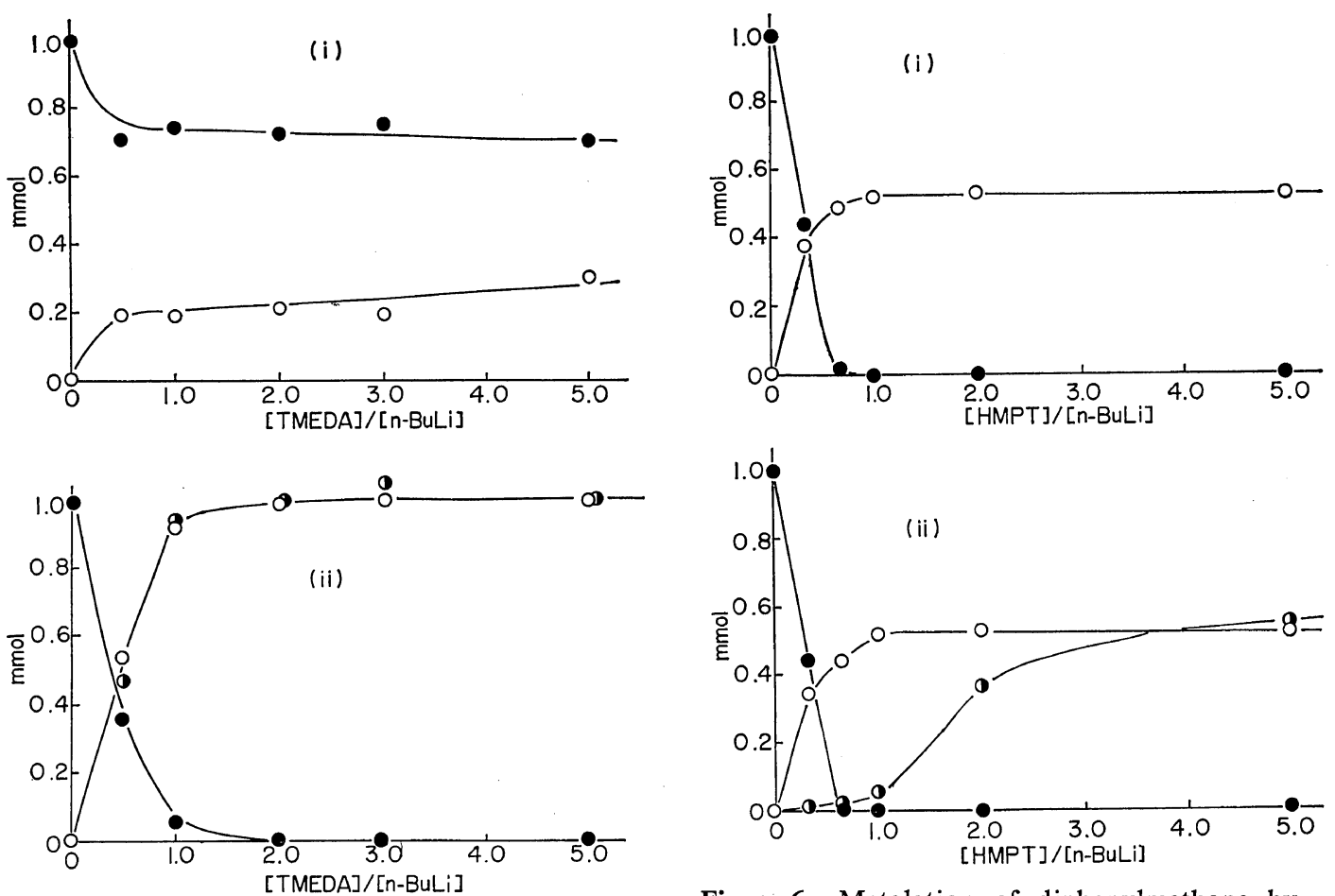

Figure 5. Metalation of diphenylmethane by $n$ BuLi-TMEDA system: (i) $n$-BuLi-TMEDA; (ii) $n$-BuLi-TMEDA- $\mathrm{Ph}_{2} \mathrm{CH}_{2} ; \bigcirc$, butane; $\bigcirc$, pentane; diphenylethane.

Reaction conditions: $n$-BuLi, $1.0 \mathrm{mmol}$; cyclohexane, $10 \mathrm{ml} ; \mathrm{Ph}_{2} \mathrm{CH}_{2}, 1.0 \mathrm{ml}$; room temp; 30 min; dimethyl sulfate(methylating agent), $1.0 \mathrm{~m} l$.

Lithium dimethylamide metalated diphenylmethane in HMPT, but not in cyclohexane. Corey, et al., ${ }^{13}$ reported that a hydrogen of $\alpha$-methylene in alkylphosphoric acid bis(dimethylamide) was metalated cleanly by $n$-BuLi (eq 8 ):

$$
\begin{aligned}
& \mathrm{O}=\mathrm{P}\left\langle\underset{\mathrm{CH}_{2} \mathrm{CH}_{3}}{\mathrm{~N}\left(\mathrm{CH}_{3}\right)_{2}}+\underset{\mathrm{CH}}{\mathrm{N}\left(\mathrm{CH}_{3}\right)_{2}}+\mathrm{BuLi}\right. \\
& \underset{-50^{\circ}, 3 \mathrm{hr}}{\stackrel{\mathrm{THF}}{\longrightarrow}} \underset{(+) \mathrm{Li}}{\mathrm{O}=\mathrm{P}}<\underset{(-) \mathrm{CHCH}_{3}}{\mathrm{~N}\left(\mathrm{CH}_{3}\right)_{2}}
\end{aligned}
$$

Accordingly $n$-BuLi seemed to react HMPT stepwise by way of an elimination-addition reaction as follows

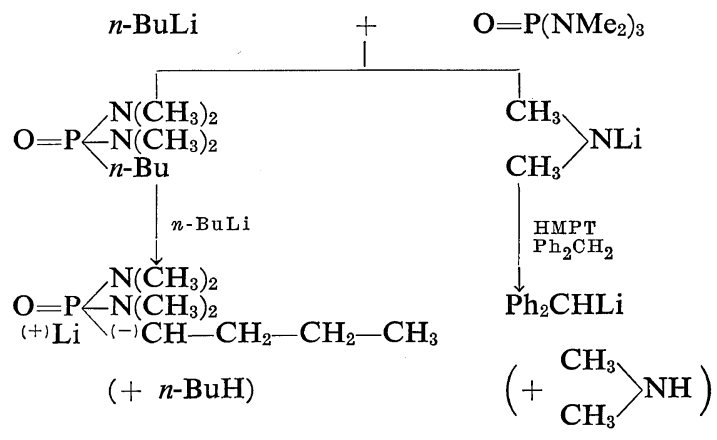

\section{CONCLUSION}

Table VI shows the main feature of the reactivity of the three catalyst systems when [complexing agent $] /[n-\mathrm{BuLi}]$ ratio equal to 2.0 . A high yield of DPPE despite the low metalation yield was quite characteristic in $n-\mathrm{BuLi}-$ 
Table VI. Comparison of reactivity of three catalyst systems

\begin{tabular}{lccc}
\hline Complexing agent & $\begin{array}{c}\text { Molar } \\
\text { ratio }\end{array}$ & $\begin{array}{c}\text { Metalation } \\
\text { yield }\end{array}$ & $\begin{array}{c}\text { DPPE } \\
\text { yield }\end{array}$ \\
\hline $\mathrm{CH}_{3} \mathrm{OCH}_{2} \mathrm{CH}_{2} \mathrm{OLi}$ & 2.0 & 16 & 62 \\
TMEDA & 2.0 & 100 & 31 \\
$\mathrm{HMPT}$ & 2.0 & 37 & 80 \\
\hline
\end{tabular}

a Molar ratio $=[$ complexing agent $] /[n-\mathrm{BuLi}]$.

$\mathrm{CH}_{3} \mathrm{OCH}_{2} \mathrm{CH}_{2} \mathrm{OLi}$. The results of both the yield of DPPE and the metalation yield of diphenylmethane suggested the importance of transmetalation reaction with diphenylmethane (eq 3). In $n$-BuLi-TMEDA system, however, the metalation reaction proceeded quantitatively but the yield of DPPE rather low. In $n-\mathrm{BuLi}-$ HMPT system, lithium dimethylamide was an active species for the metalation reaction of diphenylmethane.

\section{REFERENCES}

1. T. Narita, N. Imai, and T. Tsuruta, Kogyo Kagaku Zasshi (J. Chem. Soc., Ind. Chem. Sect.), 72, 994 (1969).
2. T. Narita, A. Masaki, and T. Tsuruta, $J$. Macromol. Sci.-Chem., A4 277 (1970).

3. T. Narita and T. Tsuruta, J. Organometal. Chem., 30, 289 (1971).

4. G. G. Eberhardt and W. A. Butte, J. Org. Chem., 29, 2928 (1964).

5. a) T. Asahara and T. Sato, Kogyo Kagaku Zasshi (J. Chem. Soc., Ind. Chem. Sect.), 71, 1523 (1968).

b) T. Asahara and T. Sato, Bull. Japan Petroleum Institute, 11, 43 (1969).

6. S. Kume, H. Saka, A. Takahashi, G. Nishikawa, M. Hatano, and S. Kambara, Makromol. Chem., 98, 109 (1966).

7. W.W. Hartman and R. Phillips, "Organic Syntheses," Coll. Vol. 2, John Wiley \& Sons, Inc., New York, N. Y., 1943, p. 232.

8. K. Ziegler, Ann., 479, 135 (1930).

9. H. Gilman and F. K. Cartledge, J. Organometal. Chem., 2, 447 (1964).

10. H. Normant, Angew. Chem. International Edition, 6, 1046 (1967).

11. A. W. Langer Jr., PolymerPreprints, 7, 132 (1966).

12. C. D. Broaddus, J. Org. Chem., 35, 10 (1970).

13. E. J. Corey and G. T. Kwiatkowski, J. Amer. Chem. Soc., 90, 6816 (1968). 